\title{
UM PROGRAMA DE CIDADANIA PARA AS ESCOLAS DO LEGISLATIVO
}

\section{A CITIZENSHIP PROGRAM FOR LEGISLATIVE SCHOOLS}

\section{UN PROGRAMA DE CIUDADANÍA PARA LAS ESCUELAS LEGISLATIVAS}

\author{
Antonio Carlos Will Ludwig ${ }^{1}$
}

Resumo: Este artigo trata da educação para o exercício da cidadania. Sua finalidade é a de apresentar uma proposta às Escolas do Poder Legislativo quanto a esta educação. Inicialmente é feita uma abordagem sobre as relações entre democracia e cidadania. Na sequência aparecem um histórico sobre a formação para a cidadania em nosso país, o papel destas escolas quanto ao preparo do cidadão e a exposição de um programa de cidadania para elas colocarem em prática. A inferência principal é a de que mesmo levando em conta as limitações e as peculiaridades dessas escolas elas têm a possibilidade de ampliar sua contribuição ao preparo dos jovens para serem cidadãos ativos.

Palavras Chave: Democracia; Formação para a Cidadania; Cidadão Passivo; Cidadão Ativo

\begin{abstract}
This article deals with education for the exercise of citizenship. Its purpose is to present a proposal to the Schools of the Legislative Power regarding this education. Initially an approach is made on the relations between democracy and citizenship. Following is a history of training for citizenship in our country, the role of these schools in the preparation of the citizen and the exposure of a citizenship program for them to put into practice. The main inference is that even taking into account the limitations and peculiarities of these schools, they have the potential to broaden their contribution to the preparation of young people to be active citizens.
\end{abstract}

Keywords: Democracy; Citizenship Training; Passive Citizens; Active Citizens

Resumen: Este artículo trata de la educación para el ejercicio de la ciudadanía. Su finalidad es la de presentar una propuesta a las Escuelas del Poder Legislativo en cuanto a esta educación. Inicialmente se hizo un enfoque sobre las relaciones entre democracia y ciudadanía. En la secuencia aparecen un historial sobre la formación para la ciudadanía en nuestro país, el papel de

\footnotetext{
${ }^{1}$ Possui licenciatura em Pedagogia, mestrado em Filosofia da Educação, doutorado em Metodologia do Ensino e pós-doutorado em Metodologia do Ensino e Educação Comparada. É professor aposentado da Faculdade de Administração Pública da Academia da Força Aérea. E-mail: emil@linkway.com.br
} 
estas escuelas en cuanto a la preparación del ciudadano y la exposición de un programa de ciudadanía para ellas poner en práctica. La inferencia principal es que incluso teniendo en cuenta las limitaciones y las peculiaridades de esas escuelas ellas tienen la posibilidad de ampliar su contribución a la preparación de los jóvenes para ser ciudadanos activos.

Palabras clave: Democracia; Formación para la Ciudadanía; Ciudadano Pasivo; Ciudadano Activo

\section{INTRODUÇÃO}

O texto que se segue visa expor uma sugestão de preparo do cidadão ativo, o qual se contrapõe à figura do cidadão passivo, às escolas do Poder Legislativo. Esta sugestão leva em conta o fato do pouco interesse das redes escolares pública e privada de nosso país em oposição ao evidente compromisso das escolas do Poder Legislativo quanto a ele.

A metodologia adotada para a sua produção foi a pesquisa bibliográfica que se baseia na procura, análise, interpretação e julgamento das contribuições teóricas existentes sobre um determinado assunto em livros, revistas e endereços eletrônicos. Ela foi complementada pela análise documental, uma técnica de investigação que possibilita identificar informações em documentos a partir de hipóteses anteriormente estabelecidas.

\section{DEMOCRACIA E CIDADANIA}

Do ponto de vista jurídico a cidadania diz respeito a uma relação entre dois entes: o indivíduo e o Estado. Nesta relação o indivíduo tem de cumprir uma série deveres para com o Estado tais como pagar impostos e prestar o serviço militar, e este tem que proporcionar um conjunto de direitos ao indivíduo tais como a educação e a saúde. Os direitos podem ser entendidos então como os benefícios que o Estado garante aos cidadãos.

Embora esta relação tenha um caráter funcional nem sempre ela encontra-se livre de certos percalços, pois tanto o indivíduo quanto o Estado podem deixar de concretizar de modo parcial ou total suas obrigações. Apesar desta possibilidade só podemos conceber a cidadania no âmbito do regime democrático o qual é sustentado pelo princípio da soberania popular. Em outros tipos de regime inexiste a figura do cidadão que é o detentor da cidadania e sim a do citadino ou o habitante da cidade.

Democracia e cidadania são ocorrências bastante antigas. Com efeito, há alguns séculos antes de Cristo o filósofo Aristóteles expôs que o governo de um determinado país pode ser concretizado por meio da monarquia cujo poder é exercido por apenas uma pessoa, através da aristocracia que diz respeito à uma minoria encarregada de tomar decisões e pela democracia, o regime político baseado em um conjunto de pessoas que gozam dos direitos de cidadania. Assim sendo são dotadas da legitimidade necessária para debater e decidir sobre questões pertinentes à 
manutenção e desenvolvimento do Estado.

Esta possibilidade de envolvimento com os problemas relativos à vida nacional mostra que a democracia não pode ser apenas representativa, ou seja, aquela que é exercida pelos que são eleitos, porque a representatividade indica que apenas alguns, isto é, os escolhidos por meio do voto, possuem a competência para tomar decisões.

No decorrer do tempo o regime democrático agregou a possibilidade de participação direta do cidadão nas questões políticas (BENEVIDES, 2000). Surgiram então o plebiscito que é uma consulta à população e cujo resultado é acatado pelo governo, o referendo que é uma ratificação ou não ratificação de uma proposta governamental, a iniciativa popular que é a elaboração de projetos de lei por uma ou mais pessoas, amparados por uma expressiva quantidade de assinaturas, o quais são submetidos ao exame e deliberação dos parlamentares e o recall que é a possibilidade de cassar e revogar o mandato de qualquer representante eleito por parte do povo.

Outra forma de aperfeiçoamento diz respeito à democracia social (BOBBIO, 2007). Ela indica uma passagem da esfera em que o indivíduo é considerado como cidadão para a esfera onde ele é considerado na multiplicidade de seus papéis. Consequentemente, a democracia deve ocupar determinados espaços normalmente dominados pela burocracia e hierarquia, como por exemplo na família, nos quartéis, na igreja, no local de trabalho e na escola. A ocupação desses espaços implica a participação de todos os integrantes no processo decisório.

A ocupação desses espaços também é de fundamental importância para a manutenção de um Estado democrático, haja vista que é muito difícil a sua sobrevivência no interior de uma sociedade cujas instituições não são gerenciadas de maneira democrática. A democracia política é imprescindível para que um povo não seja dirigido de forma despótica, mas o indicador de desenvolvimento democrático de um país não pode prescindir das instâncias onde a democracia social é posta em prática.

O conceito de cidadania referente ao usufruto de direitos e ao cumprimento de deveres não esgota seu sentido. Embora este conceito básico continue válido a ideia de cidadania pode ser ampliada. Com efeito, a observação do comportamento das pessoas na vida em sociedade mostra a existência de dois tipos de cidadãos que são o ativo e o passivo. Consequentemente a caracterização de cada um deles amplia bastante o significado de cidadania conforme veremos mais adiante.

\section{EDUCAÇÃO PARA A CIDADANIA}

O surgimento do cidadão ativo ou passivo decorre de um processo formativo. Ele inclui a vivência em grupos específicos durante a vida tais como a família e a igreja e os ensinamentos recebidos na escola. A instituição escolar, de modo intencional ou não, e por meio dos currículos real e oculto é a grande responsável por tal processo que se inicia na educação infantil e termina na universidade. Entendemos que o currículo real diz respeito a tudo aquilo que é praticado dentro 
da escola, enquanto o currículo oculto se refere a todas as aprendizagens realizadas pelos alunos que não foram planejadas pelos professores e dirigentes escolares (KELLY, 1981). Esse longo desenvolvimento educativo produz um tipo de indivíduo mais inclinado para o lado da esfera privada ou mais inclinado para o lado da esfera pública. A inclinação para um lado ou outro nos obriga a analisar os acontecimentos escolares responsáveis por ela.

A vida na escola gira em torno de um currículo que está contido em um documento legal e por causa disso ele é denominado de oficial. Porém, nem sempre este currículo é cumprido tal como está previsto. Determinadas variáveis intervenientes relacionadas à sua concretização fazem com que algum elemento dele seja suprimido, adicionado ou substituído produzindo o currículo real. Estas supressões, adições e substituições rotineiramente não chegam a desfigurá-lo em sua essência.

Juntamente com a efetivação do currículo oficial ocorre também a realização do currículo oculto que conforme já asseveramos diz respeito ao aparecimento de resultados diferentes e até divergentes dos objetivos propostos. Neste caso a desfiguração pode ser bem mais séria. Colocadas estas observações vejamos então o que o currículo oficial deve prever para a formação do cidadão.

Em primeiro lugar este currículo tem que apresentar entre suas finalidades a de formar o cidadão. Em segundo lugar tem que exibir uma lista de objetivos cognitivos, afetivos e procedimentais ligados a esta finalidade. Em terceiro lugar tem que expor as disciplinas e seus respectivos conteúdos capazes de abarcar esses objetivos. Em quarto lugar tem que indicar as estratégias pedagógicas apropriadas para fazer tais objetivos serem alcançados bem como apresentar um sistema de avaliação apropriado.

Podemos dizer que a educação escolar para a cidadania em nosso país teve seu começo nos primórdios da década de sessenta do século passado por meio de Anísio Teixeira um dos mais expressivos educadores brasileiros. Foi ele quem incluiu a matéria Organização Social e Política Brasileira no currículo do ensino médio em 1962 com vistas a possibilitar ao aluno assimilar conhecimentos de leis e questões políticas para ser capaz de interferir nas decisões pertinentes à vida em sociedade

No decorrer dos governos militares dirigentes da nossa educação a tornaram obrigatória no currículo porém não mais com o objetivo proposto por Teixeira e sim para ajudar na sustentação da ideologia da segurança nacional.

Logo após o processo de redemocratização de nosso país foi elaborada uma nova Constituição Federal promulgada em 1988. O artigo 205 do Capítulo III, Seção I que trata da educação se encontra assim redigido: “a educação, direito de todos e dever do Estado e da família, será promovida e incentivada com a colaboração da sociedade, visando ao pleno desenvolvimento da pessoa, seu preparo para o exercício da cidadania e sua qualificação para o trabalho".

Após oito anos de vigência desta Constituição veio à tona a Lei de Diretrizes e Bases da 
Educação Nacional. Seu artigo $2^{\circ}$ apresenta a seguinte redação: “a educação, dever da família e do Estado, inspirada nos princípios de liberdade e nos ideais de solidariedade humana, tem por finalidade o pleno desenvolvimento do educando, seu preparo para o exercício da cidadania e sua qualificação para o trabalho".

Duas observações devem ser feitas em relação à estes dois documentos. A primeira é óbvia e diz respeito ao fato de que a finalidade da educação proposta na Constituição é plenamente referendada na Lei de Diretrizes e Bases e nem poderia ser diferente. A segunda é a de que ambas fazem referência ao preparo para o exercício da cidadania. Destacamos aqui que a palavra "exercício" indica a realização de ações no âmbito da sociedade.

Depois de dois anos da promulgação desta Lei apareceram os Parâmetros Curriculares Nacionais do Ensino Médio. Os educadores que os elaboraram nortearam muitas propostas educativas que neles se encontram incluídas pelo objetivo de preparo para o exercício da cidadania. O mesmo pode ser dito em relação às Orientações Educacionais Complementares aos Parâmetros Curriculares Nacionais e às Orientações Curriculares Para o Ensino Médio que a eles se seguiram. Apesar desta sintonia tais educadores não tiveram a preocupação de explicitar o perfil do cidadão a ser formado, fato que não contribuiu para a instauração da necessária unidade em cada uma das áreas do currículo bem como entre elas.

Este perfil poderia ser o de cunho liberal que diz respeito à relação jurídica entre o indivíduo e o Estado em termos do usufruto de direitos e o cumprimento de deveres, poderia ser o de cunho comunitarista que é baseado na realização de ações de apoio à governabilidade e às entidades existentes no local onde a pessoa vive (BÁRCENA, 1997; HOSKINS; MASCHERINI, 2009), ou qualquer outro perfil encontrável na literatura especializada.

No ano de 2001 surgiu o Plano Nacional de Educação que propôs reduzir em cinco por cento ao ano a repetência e a evasão, atender toda a demanda num prazo de dez anos e alcançar níveis satisfatórios de desempenho segundo os critérios estabelecidos pelo SAEB e ENEM. Este plano previu para os alunos do ensino médio a “aquisição de competências relacionadas ao pleno exercício da cidadania". Para tanto instituiu o objetivo de "apoiar e incentivar as organizações estudantis, como espaço de participação e exercício da cidadania". No ano seguinte surgiram documentos intitulados `Orientações Educacionais Complementares aos Parâmetros Curriculares Nacionais' que trouxeram sugestões ao ensino das disciplinas integrantes do currículo.

Em seguida à estas duas Orientações e após alguns anos foi aprovado um Parecer que estabeleceu novas diretrizes para o ensino médio com base em diversas justificativas dentre as quais a se encontra a finalidade de preparação para a cidadania. Este parecer apenas reafirmou a finalidade em questão, porém não clarificou o seu sentido. Entretanto ele apresentou algumas propostas relativas ao protagonismo dos estudantes, ao papel dos órgãos colegiados escolares e de representação estudantil bem como a inclusão da educação ambiental e a educação em direitos humanos que são muito importantes para o preparo do cidadão. 
Cabe destacar que em relação à educação em direitos humanos o documento denominado Diretrizes Curriculares Nacionais da Educação Básica editado em 2013 previu o exercício da cidadania ativa por todos os envolvidos no processo educativo. Nele encontra-se escrito que esta cidadania diz respeito “à prática sistemática dos direitos conquistados, bem como a ampliação de novos direitos". Embora seja uma concepção substantiva e relevante ela se apresenta de maneira reduzida e pouco abrangente se comparada se à concepção por nós desenvolvida.

O ano de 2014 marcou o fim da apresentação de propostas e sugestões destinadas ao preparo do cidadão nas escolas. Com efeito, O Plano Nacional de Educação promulgado nesta data não contém nenhuma meta e consequentemente nenhuma estratégia voltada à educação para a cidadania.

No mês de fevereiro de 2017 emergiu uma nova lei sobre o ensino médio a qual tratou da alteração, regulamentação e revogação de leis anteriores e da instituição da escola de tempo integral cuja carga horária atual de oitocentas horas deverá ser ampliada de maneira crescente até alcançar mil e quatrocentas horas.

Esta Lei estabeleceu um currículo composto por uma parte comum e uma parte diversificada em função de cinco áreas relativas à Linguagens, Matemática, Ciências da Natureza, Ciências Sociais e Humanas e Formação Profissional por meio de vivências práticas de trabalho, de modo simulado ou real, e em parceria com outras instituições.

Com fundamento nos princípios da flexibilidade e da autonomia ela instituiu a diversidade de itinerários formativos e diferentes arranjos curriculares de acordo com as possibilidades dos sistemas de ensino. Recomendou que a organização das áreas deve ser feita de acordo com critérios fixados em cada sistema de ensino e que o ensino pode ser organizado através de módulos e sistemas de créditos. Determinou ainda que o currículo deverá levar em conta a formação integral do aluno nos aspectos físicos, cognitivos e socioemocionais.

Como pode ser notado esta lei tratou de vários assuntos relevantes pertinentes ao ensino médio. Concedeu uma atenção significativa ao preparo profissional do aluno e mencionou que o currículo precisa considerar também as três dimensões proporcionadoras de seu pleno desenvolvimento. Portanto, ela se mostrou sintonizada com a finalidade da educação estabelecida na Carta Magna e referendada pela Lei de Diretrizes e Bases no que diz respeito a dois de seus aspectos que são o pleno desenvolvimento da pessoa e sua qualificação para o trabalho.

No entanto quanto ao aspecto referente ao preparo para o exercício da cidadania ela é totalmente omissa pois não traz nenhum artigo, parágrafo ou inciso a seu respeito, o que é muito grave. Aliás, a palavra cidadania não aparece em nenhuma parte do texto. Assim sendo não dá para inferir se seus autores a consideraram como um conceito primitivo, um subentendido ou um pressuposto.

Em novembro de 2018 veio à tona uma resolução destinada a atualizar as diretrizes curriculares nacionais para o ensino médio. É possível deduzir também que diante do exagerado 
destaque que ela concedeu à qualificação para o trabalho bem como à marcante presença do ideário pós-moderno, o preparo para o exercício da cidadania apresenta-se evidentemente em segundo plano. O que se pode perceber é a ausência de um translúcido conceito de cidadania , a falta de um significado a respeito do ato de exercitar a cidadania, a carência de um perfil de cidadão que se almeja formar, e, consequentemente, a inexistência de delineamento de uma coerente estratégia pedagógica destinada ao ensino e à aprendizagem da cidadania.

No mês subsequente emergiu o derradeiro documento que vai nortear todo o ensino médio, ou seja, a base nacional comum curricular. Nele o tema da cidadania é tratado de forma diferenciada. $\mathrm{O}$ que se percebe de imediato é a ausência de um conceito de cidadania devidamente explicitado e teorizado, atravessador das quatro áreas do conhecimento em que ele se baseia. Tal como já foi dito, a ideia de cidadania aparece muitas vezes de modo subentendido e como fundamento de proposituras variáveis. Nota-se, também, a existência de concepções peculiares pressupostas em cada uma das áreas do conhecimento.

Consideramos bastante preocupante a ausência de diretrizes claras pertinentes à formação para a cidadania nestes documentos, particularmente quanto ao preparo do cidadão ativo conforme o entendimento que adotamos. A esse respeito vale destacar que a nossa Constituição valoriza significativamente a figura do cidadão ativo porquanto prevê o instituto da democracia direta através da realização de plebiscitos, referendos e projetos de iniciativa popular. Pensamos também que esta ausência colabora sobremaneira para a ocorrência de um déficit na formação de pessoas para o regime democrático principalmente no que tange à eliminação ou pelo menos a barragem do avanço da promiscuidade entre o público e o privado que é ostensiva em nosso país.

\section{CIDADÃO PASSIVO E ATIVO}

Ressalte-se que a educação para a cidadania constitui preocupação essencial nos países europeus. Desde 2010 todos os países da Comunidade Europeia estão colocando em prática nas escolas um programa para formar cidadãos. Ele é considerado muito importante haja vista que possui um currículo específico, cursos destinados à formação de professores e dirigentes escolares e controle centralizado.

Nos Estados Unidos da América do Norte, embora não haja um programa semelhante, pois a educação deste país é regida pelos princípios da autonomia e da descentralização, muitas escolas estão comprometidas com o preparo do cidadão. Pesquisas já realizadas revelaram que as instituições educativas estadunidenses tem contribuído para a formação de cidadãos pessoalmente responsáveis, participativos e orientados para a justiça social.

Tanto na Europa quanto nos Estados Unidos um dos tipos de cidadão que está sendo formado é o ativo que se contrapõe ao passivo. Cada um desses dois tipos apresentam determinadas características que lhes são próprias, as quais permitem diferenciar um do outro.

Vale lembrar que a nossa Carta Magna em seu artigo primeiro, parágrafo único prevê que 
"todo poder emana do povo, que o exerce por meio de representantes eleitos ou diretamente nos termos desta Constituição". No artigo catorze encontra-se escrito que "a soberania popular será exercida pelo sufrágio universal e pelo voto direto e secreto, com valor igual para todos, e, nos termos da lei, mediante: $\quad$ I - plebiscito; II - referendo; III - iniciativa popular". Estes dizeres evidenciam claramente que o tipo de cidadão que se encontra pressuposto é o ativo.

Cidadania ativa e passiva são conceitos consagrados e importantes da teoria política. O nosso entendimento a respeito de ambos se apresenta como uma síntese de muitos autores, tais como: ARENDT, 2007; BÁRCENA, 1997; BENEVIDES, 2000; GIROUX, 1998; GRAMSCI, 1978; HABERMAS, 1984; HOSKINS; MASCHERINI, 2009; LACLAU e MOUFFE, 2015; MARX, 1986; POULANTZAS,1985; e SANTOS, 2002.

Baseado nesses textos concebemos então que o cidadão passivo refere-se à pessoa que por determinados motivos prefere realizar sua existência, predominantemente, no âmbito da esfera privada que é o setor restrito e reservado da vida em sociedade onde valem os interesses particulares, onde prevalece a exigência da sobrevivência, onde a intimidade se concretiza e onde a visibilidade e a transparência se encontra reduzida ao máximo possível. Esta esfera inclui alguns espaços existentes na comunidade tais como o local de trabalho e a vida familiar. O cidadão passivo também é uma pessoa que costuma cumprir seus deveres para com o Estado e normalmente aceita ser governado por outros.

Por sua vez consideramos que o cidadão ativo é o indivíduo que se julga governante. Além de estar inserido na esfera privada, realizar as atividades do cidadão passivo e cumprir suas obrigações para com o Estado frequentemente encontra-se presente na esfera pública que é o setor da vida em sociedade acessível a todas as pessoas, onde predomina o interesse geral e a visibilidade e a transparência são ampliadas até os seus limites. Nela valem o diálogo, a comunicação, o discurso, a argumentação e a ação conjunta que pode se voltar para o objetivo de influenciar as decisões políticas. Esta esfera inclui certos espaços sociais tais como as ruas e as praças onde assuntos que se relacionam com a vida de todos são examinados e debatidos.

Este tipo de cidadão além de lutar pelos seus direitos e interesses costuma realizar ações individuais e grupais em benefício da coletividade, principalmente aquelas relacionadas aos direitos outorgados e prioritariamente as que favorecem os segmentos desprivilegiados da sociedade. Ele não admite comportar-se apenas como uma pessoa governada pois também almeja ser governante. Como pode ser percebido este conceito de cidadania ultrapassa a mera relação jurídica entre o indivíduo e o Estado, embora não a negue. Observe-se também que estes dois tipos de cidadão não são excludentes porquanto inexiste qualquer fator capaz e impedir que o passivo se torne ativo e o ativo se torne passivo. Note-se ainda que as esferas privada e pública não se apresentam de modo estanque pois podem ocorrer intersecções entre elas.

Sua ação, sempre consoante ao regime democrático, pode ser local, regional, estadual, nacional e também internacional porquanto o espaço de participação disponível encontra-se 
globalizado. No âmbito da esfera pública, onde se encontram grupos de pessoas ele se utiliza de seus conhecimentos e de e de sua oratória como recursos para se alcançar as decisões mais adequadas.

Portanto, parece fácil inferir que a sociedade atual tem que possuir uma grande quantidade de cidadãos ativos, quiçá todos, pois neles reside a esperança de que os direitos conquistados a duras penas não venham a ser suprimidos ou aviltados por causa de decisões políticas.

Porém, a importância do cidadão ativo não se restringe apenas à defesa dos direitos. Sendo um indivíduo que sabe bastante, encontra-se sempre em estado de alerta e em atitude de vigilância. Por causa disso a existência de certos males tais como o nepotismo, o conchavo, os privilégios, o apadrinhamento, a não transparência, a impunidade, a centralização, o populismo, a demagogia e o personalismo de governantes tornam-se mais difíceis de se manter.

A presença do cidadão ativo favorece o surgimento de decisões políticas mais adequadas e consequentemente mais acatáveis por todos. Seu protagonismo beneficia a governabilidade, auxilia a legitimação, o fortalecimento e a valorização do regime democrático além de contribuir para a perenidade e a vitalidade deste regime. Vale realçar também que é significativo seu poder de fogo contra as injustiças e desigualdades sociais.

No regime democrático representativo a figura do cidadão ativo é imprescindível por causa de suas inúmeras fragilidades. Dentre elas podemos mencionar a ocorrência do desrespeito por parte dos eleitos quanto aos compromissos assumidos anteriormente; o progressivo distanciamento entre governantes e governados; a presença de um déficit de credibilidade por parte de muitos políticos que veem a sociedade como uma massa manobrável; a manifestação do uso excessivo das forças de coação, manipulação dos meios de comunicação, emprego da mentira e de corrupção; o avanço do poder executivo sobre o legislativo e o deliberado empenho em obstaculizar as diversas formas de participação popular. Acrescente-se a isso o surgimento de diversas esferas supranacionais de poder resultante do processo de globalização.

Tal como vimos anteriormente, tanto o Plano Nacional de Educação editado em 2014 como a última lei promulgada em fevereiro deste ano que dentre outros tópicos instituiu a escola de tempo integral, não há nenhuma referência ao preparo para a cidadania. Entretanto, esta lei preocupou-se ostensivamente com a formação profissional do aluno. Esta preocupação demonstra claramente que seus autores estão interessados apenas em formar pessoas alienadas da vida política do país. Embora de maneira não explícita a lei em questão se encontra realmente comprometida com o preparo do cidadão passivo.

Apesar desta lei e do futuro currículo é notório que em muitas escolas de ensino médio de nosso país estão se concretizando e deverão continuar se concretizando diversas práticas pedagógicas favoráveis à formação do cidadão ativo. Dentre outras mencionamos a gestão escolar democrática e o planejamento participativo que é responsável pela elaboração do projeto político pedagógico. Entretanto estas práticas raramente se encontram intencionalmente articuladas à 
proposta de formação do cidadão ativo.

Devemos lembrar também que existem práticas na vida em sociedade tais como o trabalho voluntário e o envolvimento em movimentos sociais que não só comprovam a existência mas aperfeiçoam a conduta do cidadão ativo. Acrescentamos ainda a importante presença das Escolas do Legislativo que por meio de práticas apropriadas estão contribuindo significativamente para o preparo deste tipo de cidadão.

\section{ESCOLAS DO LEGISLATIVO E FORMAÇÃO PARA A CIDADANIA}

Recorrendo à história constatamos que as Escolas do Legislativo possuem uma origem recente. O dinamismo e o desenvolvimento dessas escolas se encontram relacionados ao surgimento da reforma administrativa de 1998. Tendo em vista a qualificação dos servidores federais bem como sua promoção em carreiras específicas ela deu origem às Escolas de Governo. Um de seus artigos assevera que cabe à União, aos Estados e ao Distrito Federal manterem Escolas de Governo destinadas à formação e ao aperfeiçoamento dos agentes públicos. Nesse artigo encontra-se previsto também que cabe aos Municípios criarem um conselho de política de administração e remuneração de pessoal.

Esta reforma teve o poder de ensejar a regulamentação das atividades das escolas congêneres no âmbito do Poder Judiciário e do Poder Legislativo. Entretanto, cabe lembrar que a Escola Nacional de Administração Pública já existia antes da reforma administrativa, sendo que no ano de 1989 foi editado um decreto que a tornou a instância coordenadora e supervisora de todos os programas de capacitação desenvolvidos pelas demais escolas da administração federal.

Em consequência o Poder Judiciário também regulamentou suas escolas em 2004 através de uma resolução que conferiu à Escola de Formação e Aperfeiçoamento de Magistrados a competência para normatizar seu modelo educacional. O Poder Legislativo, particularmente o Senado Federal, criou em 1997 o Instituto Legislativo Brasileiro para capacitar seus servidores, em 1999 o Interlegis que é um programa de integração e modernização do Poder Legislativo e em 2001 a Universidade do Legislativo Brasileiro.

A Câmara dos Deputados instituiu o Centro de Formação, Treinamento e Aperfeiçoamento em 1997 também voltado para a finalidade de capacitação. No ano de 2003 emergiu a Associação Brasileira de Escolas do Legislativo e de Contas capitaneada pelo Senado que dentre seus objetivos aparece o de se aproximar dos diversos segmentos da sociedade organizada. Tal associação obteve a tarefa de estabelecer uma política educacional nacional, embora em caráter orientador e fomentador e não impositivo.

Esta aproximação constituiu um aspecto muito importante das Escolas do Legislativo e as tornam diferenciadas de suas congêneres que pertencem ao Executivo e ao Judiciário. Com efeito, tal peculiaridade indica que além de se voltarem para a capacitação de seus integrantes elas pretendem ofertar um espaço à comunidade, ao cidadão comum, às múltiplas organizações 
sociais, à iniciativa privada e às instituições educativas. Este espaço envolve cursos, palestras, seminários, elaboração de projetos e simulação de atividade parlamentar com vistas a buscar uma compreensão mais apurada da estrutura e do funcionamento do Poder Legislativo bem como proporcionar uma educação política democrática.

Vale destacar que a primeira Escola do Legislativo foi a do Estado de Minas Gerais porquanto ela foi criada em 1993. Após ela seguiram-se as dos Estados de Pernambuco, Santa Catarina e Rio Grande do Sul. No portal da Associação Brasileira encontra-se registrado a existência de Escolas do Legislativo em todos os Estados brasileiros e em mais de cem municípios integrantes desses Estados, cuja maioria pertence a Minas Gerais e São Paulo.

Ao visitar os portais eletrônicos de algumas dessas escolas é possível constatar em seus regulamentos a diretriz de aproximação com a comunidade. No Estado de São Paulo a de Campinas propõe duas metas: desenvolver programas de ensino, objetivando a integração da Câmara com a sociedade civil organizada e capacitar a comunidade em temas relacionados às atividades institucionais do Poder Legislativo, podendo promover palestras, oficinas e seminários. A de Juiz de Fora em Minas Gerais propõe a formação e a qualificação de lideranças comunitárias e políticas, bem como o desenvolvimento de ações de capacitação para a cidadania, visando promover uma melhor compreensão do Poder Legislativo e das práticas políticas e legislativas. A de Caxias do Sul no Rio Grande do Sul objetiva promover a aproximação entre o Poder Legislativo e a sociedade, por meio de programas direcionados para a educação política, para a formação de lideranças comunitárias e para o exercício da cidadania e aproximar o Poder Legislativo do ensino fundamental, médio e superior.

Este intento de aproximação com a comunidade tem se confirmado na prática, haja vista o que já foi e continua sendo feito por muitas dessas escolas. Na Câmara dos Deputados em Brasília, por exemplo, tem-se o Parlamento Jovem, o Estágio Visita, o Estágio Cidadão e os Programas de Visitação Pedagógica e Missão Pedagógica no Parlamento. Na Escola do Legislativo de Santa Rita de Caldas em Minas Gerais os alunos do ensino médio trabalharam o tema relativo à organização do Estado por meio de mesas redondas, debates e peças teatrais. A de Itajubá, também em Minas Gerais desenvolveu o Programa Cidadania e Conscientização Política. A de Belo Horizonte concretizou um ciclo de palestras intituladas Segurança Pública e Direitos Humanos, Prevenção Social do Crime e Novas Perspectivas Para a Ação Policial. A de Araraquara em São Paulo realizou um Curso de Formação Política para estudantes do último ano do ensino fundamental. Atividades semelhantes estão sendo postas em práticas em muitas outras escolas do legislativo e isto pode ser constatado visitando seus portais na Internet.

Dentre estas escolas concedemos realce ao Centro de Formação, Treinamento e Aperfeiçoamento da Câmara dos Deputados que possui um programa denominado Missão Pedagógica do Parlamento. Após concluírem um curso presencial e à distância neste centro um grupo de professores elaborou o livro `Educação Para a Democracia: Projetos Inspiradores das 
Professoras e Professores do Brasil’’, o qual foi organizado por Otávio da Silva e Marina Diniz. Nesta obra encontram-se relatos de experiências atuais voltadas para a formação do cidadão ativo. Vejamos algumas delas na área do ensino médio.

Na cidade de Maragogi, Estado de Alagoas a professora Fabrícia Silva trabalhou com os alunos o envio de cartas aos vereadores relativas aos problemas existentes no munícipio, as quais foram entregues no momento de uma visita à Câmara Municipal.

A professora Izabelly Fernandes, em Campina Grande Estado do Paraíba, desenvolveu junto aos discentes uma atividade de combate à Dengue a qual contou com a colaboração das Secretarias da Saúde do Estado e do Município.

As professoras Maria Fonseca e Meire Bastos da cidade de Araguaína Estado do Tocantins, desenvolveram com os alunos a tarefa de produção de vídeos sobre possíveis melhorias a serem implantadas na comunidade os quais foram entregues à Câmara dos Vereadores.

Marina Diniz, professora da cidade de Santa Inez Estado do Maranhão, trabalhou com os alunos o tema dos Direitos Humanos. Após elaborarem uma cartilha sobre este assunto ela foi divulgada nas escolas e na comunidade por meio da rádio local.

Vale destacar que a Associação Brasileira das Escolas do Legislativo a qual congrega as instituições educativas do Poder Legislativo Brasileiro nos níveis federal, estadual e municipal tem como um de seus objetivos estimular, divulgar e fortalecer programas de educação para a cidadania desenvolvido pelas escolas como forma de apoio às comunidades e à sociedade civil.

Frente a estas ocorrências torna-se claro que as Escolas do Legislativo assumiram, na intenção e na prática, a tarefa de formar as pessoas para o exercício da cidadania ativa embora sua ação principal continue sendo a capacitação de seus servidores. Assim sendo, parece-nos que não cabe a apresentação de qualquer tipo de questionamento quanto à função que devem desempenhar no âmbito da educação para a democracia.

Concretamente elas estão dando uma valiosa contribuição complementar ao pouco que vem sendo feito em escolas das redes pública e privada de ensino quanto à formação do aluno para o desempenho de seu papel de cidadão. Também estão preenchendo uma lacuna relativa à esta formação por parte das escolas que se encontram em estado de omissão intencional ou não quanto a esta tarefa, principalmente porque as legislações educacionais recentes também tem sido omissas a esse respeito.

Pensamos, entretanto, que as Escolas do Legislativo são donas de um potencial bastante elevado com vistas a proporcionar uma educação para a cidadania de modo mais extenso e substantivo. Muitas delas possuem um corpo qualificado de funcionários e um grupo de vereadores e deputados experientes, portadores de títulos universitários e versados em vários assuntos. Por iniciativa de seus dirigentes podem conseguir facilmente o apoio de organizações existentes na comunidade e região, principalmente faculdades e universidades, cujos integrantes se encontram disponíveis e interessados em atuar de maneira totalmente voluntária nesta 
modalidade educativa. Como exemplos podemos mencionar a Pontifícia Universidade Católica e a Universidade Estadual Paulista que respectivamente colaboram com as Escolas do Legislativo de Minas Gerais e da cidade de Araraquara em São Paulo. A experiência tem demonstrado também que as próprias escolas onde os alunos estudam apoiam as iniciativas das casas legislativas quanto à formação política de seus alunos.

Uma das atividades mais comum e frequente realizadas pelos discentes das séries finais do ensino fundamental e das três séries do ensino médio tem sido a simulação de ações rotineiras praticadas pelos vereadores e parlamentares, particularmente a elaboração de projetos a serem submetidos à apreciação em plenário. Ela é muito relevante pois muitos deles já foram aprovados e transformados em lei trazendo benefícios à coletividade. Vale lembrar que em muitos países europeus (REDE EURYDICE, 2017) e nos Estados Unidos da América do Norte (WESTHEIMER, 2015) esta atividade é constantemente praticada pelos discentes das instituições educativas. Além desta existem outras que raramente são concretizadas sob os auspícios das escolas do poder legislativo as quais apresentamos como sugestões e esperamos que venham a ser devidamente acolhidas.

\section{SUGESTÕES ÀS ESCOLAS DO PODER LEGISLATIVO}

Concebemos que uma das mais importantes delas diz respeito às Campanhas Cívicas. Estas ações além de produzirem resultados altamente positivos para a comunidade e ao governo local têm o poder de forjar e aperfeiçoar a atitude de dedicação ao interesse público, de atentar para o bem estar coletivo, de respeitar e valorizar a coisa pública e de zelar para que ela seja bem gerenciada por aqueles que foram escolhidos pelo povo.

Observe-se que tal atitude encontra-se bastante diminuída em nosso país haja vista a corrupção generalizada presente nas instâncias municipal, estadual e federal porquanto muitos políticos não conseguem ostentar uma postura republicana, não sabem ou não querem diferenciar o público do privado e nem obedecem o princípio da publicidade da esfera administrativa previsto em nossa Carta Magna. Tais campanhas visam a aquisição de máquinas e instrumentos para as prefeituras bem como a reparação e a conservação das mesmas. Visam também a construção e a preservação de logradouros públicos.

As Campanhas de Sensibilização também são muito relevantes. Elas dizem respeito ao ato de intervir no campo das emoções e da afetividade das pessoas, de levá-las a perceberem as coisas de modo diferente, de sentir o que antes não sentiam, de internalizar determinadas informações e refletir sobre elas. Estas campanhas se voltam para o combate ao fumo, ao alcoolismo, ao uso de drogas e ao boicote a produtos inadequados. O consumo do álcool em doses elevadas tende a provocar consequências deletérias imediatas. O uso do tabaco contribui sobremaneira para o encurtamento da vida e a utilização de drogas inclina-se a acarretar danos cerebrais irreversíveis.

Os produtos inadequados ao consumo favorecem o aparecimento de câncer, de doenças 
respiratórias, de doenças cardiovasculares e da diabetes, além estarem relacionados ao aumento da obesidade. A esse respeito vale destacar a fala do diretor geral da Organização Mundial da Saúde na abertura da última Conferência Mundial realizada em Montevidéu, no Uruguai em outubro de 2017. Segundo ele “em nome do livre comércio nós permitimos que as empresas alimentares envenenem as pessoas". Na sequência questionou: "quando tomaremos posição e pressionaremos os fabricantes desses produtos?"

Lembramos que o vício em cigarro, álcool e drogas bem como o consumo de produtos inadequados não constitui um problema pessoal apenas, haja vista que as consequências extrapolam os planos individual e familiar. A maioria das pessoas que adquirem doenças por estes motivos procuram os órgãos do Estado para conseguir os tratamentos necessários. Muitos recursos públicos oriundos da contribuição de milhares de cidadãos são canalizados para estes tratamentos. Mencione-se ainda a concessão do auxílio doença para aqueles que se encontram temporariamente incapazes para o trabalho e a aposentadoria por invalidez devido à uma deficiência que impede totalmente a realização da atividade ocupacional. Supomos que cabe a cada pessoa cuidar bem de sua saúde para não onerar os cofres públicos e possibilitar o aceso de todos ao dinheiro disponível nos momentos de necessidade.

As Campanhas Filantrópicas são aquelas voltadas para a busca de donativos tais como roupas, comida, dinheiro, materiais diversos, aparelhos e instrumentos para instituições da comunidade, organizações não governamentais, grupos de pessoas ou um determinado indivíduo. Cabe realçar que a filantropia se encontra bastante disseminada em vários países do mundo. Os Estados Unidos da América do Norte se encontram na primeira posição perante as demais nações porquanto ela está fortemente enraizada em sua cultura. Empresas, fundações e famílias destinam dezenas de bilhões de dólares à filantropia anualmente.

No Brasil a cultura da mesma está sendo paulatinamente desenvolvida por meio da iniciativa de pessoas físicas e jurídicas. Não há dúvida de que os atos de generosidade produzem um impacto na sociedade bastante significativo porquanto carreia benefícios a muita gente além de se constituir num poderoso auxílio ao Estado que sozinho não é capaz de dar conta de todos os problemas sociais existentes.

As Campanhas de Defesa do Meio Ambiente se apresentam como algo extremamente necessário e urgente face à ameaça concreta e iminente do aumento do aquecimento global que pode trazer graves consequências para a humanidade. Esta ameaça tem obrigado todos os países a defenderem e adotarem políticas de desenvolvimento compatíveis e adequadas. Uma série de doenças decorre da degradação do meio circundante tais como a febre amarela, a tuberculose, a peste bubônica e a malária. Caso não haja políticas a ela destinadas os custos para o Estado serão cada vez mais elevados para atender os doentes e manter os inválidos.

Devemos lamentar profundamente a aprovação pela Câmara dos Deputados da Medida Provisória relativa ao tratamento tributário concedido ao setor de exploração do petróleo e do gás 
natural em novembro de 2017 porquanto o premiou com incentivos os quais gerarão uma gigantesca renúncia fiscal. Ela revela o descaso do governo para com o clima e desconsidera os impactos na biodiversidade e na vida das pessoas num momento em que muitos países do mundo estão apoiando ostensivamente o combate ao aquecimento global.

No que diz respeito a estas campanhas é preciso ter em mente que existem pessoas e grupos que pensam de maneira diferente. Há aqueles que se intitulam conservacionistas porquanto defendem que o meio ambiente e seus recursos precisam ser geridos e utilizados de forma responsável com vistas não só ao atendimento das necessidades atuais, mas, principalmente em relação às das gerações futuras. Outros se denominam preservacionistas porque consideram que os recursos naturais devem ser mantidos intactos. Desde que se leve em conta que por determinados motivos apenas algumas áreas devem realmente permanecer invioladas ambas as posições não são contraditórias.

As Campanhas de Combate à Discriminação e ao Preconceito são imprescindíveis para a garantia, a perenidade e o fortalecimento do regime democrático o qual é um compromisso essencial do cidadão ativo. Destaque-se que em seu preâmbulo a nossa Constituição aponta a finalidade de "assegurar o exercício de direitos sociais e individuais, a liberdade, a segurança, o bem estar, o desenvolvimento, a igualdade e a justiça como valores supremos de uma sociedade fraterna, pluralista e sem preconceitos, fundada na harmonia social e comprometida com a solução pacífica das controvérsias".

No artigo primeiro define como um de seus fundamentos "a dignidade da pessoa humana". No artigo terceiro institui os objetivos de "construir uma sociedade livre, justa e solidária" e “promover o bem de todos, sem preconceitos de origem, raça, sexo, cor, idade e quaisquer outras formas de discriminação" e no artigo quinto estabelece que "todos são iguais perante a lei, sem distinção de qualquer natureza, garantindo-se aos brasileiros e estrangeiros residentes no país a inviolabilidade do direito à vida, à liberdade, à igualdade, à segurança e à propriedade".

Estes tópicos substanciais de nossa Carta Magna apontam claramente para a emergência e a manutenção de uma sociedade de caráter pluralista, assentada no princípio da fraternidade, no ideal de acolhimento de qualquer pessoa, no respeito às diferenças e no convívio relativamente harmonioso entre todos. Tal sociedade só pode ser mantida num contexto destituído de preconceitos e discriminações os quais acarretam sérios danos à paz e à convivência coletiva.

O Trabalho Voluntário embora guarde semelhanças com a filantropia é uma atividade mais ampla. Ele envolve a disponibilização de um tempo pessoal recorrente para a realização de determinadas tarefas sem receber nada em troca. Nos Estados Unidos da América do Norte os dados apontam que metade das pessoas adultas, ou seja, mais de noventa milhões delas, encontram-se atualmente envolvidas com o trabalho não remunerado, destinando a ele mais ou menos quatro horas semanais em instituições religiosas, escolas, asilos, hospitais e organizações não governamentais. Há, inclusive, incentivos fiscais por parte do governo a aqueles que se 
dedicam a ele. Estes incentivos foram capazes de provocar a criação de dezenas de milhares de fundações e quase um milhão e meio de entidades sem fins lucrativos.

$\mathrm{Na}$ atualidade o trabalho voluntário é realizado em todos os países da Europa. Estima-se que mais de cem milhões de pessoas encontram-se, nos dias de hoje, envolvidas em atividades de voluntariado, ou seja, aproximadamente vinte e três por cento da população acima de quinze anos. Considerando que o trabalho voluntário tem um peso significativo na economia europeia o Parlamento Europeu aprovou em 2008 um relatório que concede a ele todo o apoio possível.

Tal relatório convida os Estados a facilitarem o acesso das organizações de voluntariado aos programas de financiamento seja para fins administrativos ou para projetos e incentiva as empresas comprometidas com a responsabilidade social a apoiarem financeiramente as iniciativas de estímulo e reforço do trabalho voluntário. Ressalte-se ainda que a União Europeia criou e mantêm financeiramente o Serviço Voluntário Europeu destinado a jovens com idades entre dezoito e trinta anos pelo prazo de até doze meses. Seu orçamento permite a participação anual de milhares deles e o campo de atuação envolve a cultura, o desporto, a assistência social, o ambiente e vários outros setores.

Em nosso país na última década do século passado começaram a surgir as Organizações não Governamentais. $\mathrm{O}$ exponencial crescimento de tais entidades fez com que elas passassem a abrigar a maior parte do trabalho voluntário o qual está sendo considerado um item relevante no momento da procura de um emprego remunerado. Existem hoje no Brasil milhares de Organizações não Governamentais. Quase setenta por cento delas se encontra localizada na região sudeste. As demais regiões dividem o restante deste percentual. Também contam-se aos milhares o número de pessoas que nelas atuam voluntariamente.

Quanto à tipologia existem as que se dedicam à defesa dos direitos, as voltadas para o oferecimento de ajuda e caridade e as produtoras de serviços nas áreas da educação e da saúde. Os dados mais recentes apontam que apenas três em cada dez brasileiros já praticaram alguma atividade voluntária. Dentre os motivos alegados para a não realização dela encontram-se a falta de tempo, a ausência de convite, o não pensamento a respeito do assunto e o desconhecimento relativo às fontes de informação sobre o voluntariado. As próprias repartições administrativas das prefeituras podem abrigar o trabalho voluntário tais como as escolas de ensino fundamental e as bibliotecas municipais.

A Apresentação de Sugestões e Cobrança a Políticos constitui uma importante tarefa do cidadão ativo. Para colocá-la em prática ele precisa estar ciente a respeito do desempenho apresentado pelos representantes que ajudou a eleger bem como necessita acompanhar periodicamente suas ações, discursos e iniciativas. As sugestões e cobranças podem ser feitas diretamente por meio de contato pessoal ou indiretamente através de documentos e recursos eletrônicos. Observe-se que o comportamento dos políticos pode ser significativamente alterado e moldado em função desta recorrente conduta manifestada pelos eleitores. 
É possível que este contato mais achegado e constante ajude a diminuir o grande distanciamento hoje existente entre eleitores e eleitos, bem como venha a colaborar para a alteração da imagem atual de nossos parlamentares que segundo a última pesquisa realizada pelo Data Folha em novembro de 2017 receberam os conceitos de ruim e péssimo por sessenta por cento dos consultados. Parece certo que tal ato de sugerir e cobrar tende a contribuir também para a melhora do intitulado 'Índice de Percepção Equivocada' o qual é relativo à interpretação que os indivíduos fazem a respeito das peculiaridades do local em que vivem, haja vista que nosso país é o segundo de todo o planeta onde os indivíduos apresentam a percepção mais equivocada da realidade.

O Projeto Ouvindo a Voz da Comunidade constitui uma das formas de fazer sugestões e cobranças a políticos. Ele envolve o deslocamento dos alunos em direção às ruas do município para entrevistar as pessoas a respeito de suas demandas, insatisfações e propostas. Após registrálas e organizá-las elas podem ser encaminhadas para os meios de divulgação ou seja, os jornais e as rádios da cidade bem como os canais regionais de televisão. Ao mesmo tempo são enviadas aos poderes executivo e legislativo com vistas à obtenção do devido retorno.

A Elaboração de Petições Públicas apesar de poderem ser empregadas como uma forma de cobrança a políticos, podem também ser dirigidas à outras instâncias e destinatários. Quanto a elas a Constituição Federal assegura que qualquer cidadão tem o direito de elaborá-las por meio da coleta de assinaturas de um conjunto de pessoas com vistas a qualquer demanda que considere conveniente ou necessária.

Tais petições podem incluir a proposta de realização de melhorias em certos locais, o encaminhamento de reclamações a determinadas entidades e organizações da sociedade, o apoio a diversas causas sociais, a manifestação de protesto contra algo que não se concorda e a sugestão de alteração de leis que se encontram em processo de elaboração ou que já estejam em vigor. Lembramos que a feitura de petições em nosso país é bastante significativa.

A Elaboração de Moções é uma atividade semelhante à confecção de petições. A moção pode ser vista como um documento coletivo direcionado às autoridades que têm o poder de tomar decisões. Neste entendimento sua finalidade é a de ganhar o apoio para a concretização de uma ideia ou alternativa. Entretanto ela pode ser vista também como um documento que expressa o sentimento, o estado emocional de um determinado grupo de pessoas. Assim sendo seu objetivo é o de tornar registrado e público a posição assumida por este grupo. Embora ela esteja intimamente associada ao trabalho dos integrantes do poder legislativo qualquer pessoa pode tomar a iniciativa de elaborá-la e encaminhá-la ao destinatário pertinente.

Assim como as petições as moções também tem alcançado um volume elevado principalmente por causa da existência de várias modalidades. Dentre os diversos tipos existentes mencionamos como exemplos as moções de apelação que são endereçadas à uma autoridade específica para que ela tome as providências requeridas, as de repúdio ou de rejeição a decisões 
ou ações em andamento e as de apoio ou de aprovação de condutas ou deliberações.

Uma das atividades mais consoante ao funcionamento do Poder Legislativo diz respeito à criação por parte dos alunos, sobe a orientação dos vereadores, de Projetos de Iniciativa Popular. Lembramos que em nível nacional uma delas apareceu em 1994. Ela veio à tona em decorrência do assassinato da atriz Daniela Perez filha de Glória Perez. O ano de 1997 registrou o surgimento de outra patrocinado pela Comissão Brasileira Justiça e Paz filiada à Conferência Nacional dos Bispos do Brasil voltada para o combate à corrupção eleitoral. Em data mais próxima, os integrantes do Movimento de Combate à Corrupção Eleitoral tomaram a iniciativa de elaborar um projeto que foi sancionada no ano de 2010 com título de Lei da Ficha Limpa. A proposta de iniciativa popular mais recente diz respeito à aquela elaborada pelos servidores do Ministério Público Federal em decorrência da Operação Lava jato.

A Participação em Movimentos Sociais se apresenta como um importante recurso não violento do cidadão ativo. Entendemos que movimento social diz respeito a uma ação coletiva voltada para a busca de determinados objetivos ou a concretização de certos interesses. Os movimentos sociais muitas vezes se manifestam como atividades de contestação e protesto acirrados ou como exigências veementes porque outros meios não se revelaram suficientes para a consecução dos intentos almejados. Sua ocorrência é muito frequente em quase todos os países do mundo, fato que pode ser constatado apenas pela leitura de jornais.

Estudos relativos aos movimentos sociais mostram que a participação do povo brasileiro na vida social e política do país vem desde o século dezoito e todos eles contribuíram para a construção da nossa cidadania. Assim sendo todas as participações em movimentos a partir desta época até os dias de hoje podem ser considerados como exercício e aprendizado da cidadania ativa. $\mathrm{O}$ volume e os tipos de movimento mostram uma semelhança da atuação de nós brasileiros com os norte-americanos e europeus.

Embora seja muito raro em qualquer país democrático emergir as condições para a manifestação da Desobediência Civil, ela também constitui um recurso do cidadão ativo. A desobediência civil se refere ao ato de não acatar a legislação vigente e nem se submeter às decisões emanadas das autoridades constituídas desde que todos os canais de reivindicação tenham sido esgotados e desde que esteja havendo desrespeito à ordem constitucional. Podemos dizer que a desobediência civil pode ser considerada o instrumento não violento mais extremo disponibilizado ao cidadão. Apesar de ser quase dispensável o seu uso num regime democrático em funcionamento pleno, todo indivíduo deve ter o conhecimento de sua existência e aplicabilidade.

A Vida Partidária objetiva o conhecimento do ideário de cada partido com representantes nas Câmaras e Assembleias, a possível opção pela filiação e o acompanhamento das atividades partidárias. A implementação do envolvimento dos jovens com a dinâmica dos partidos se apresenta como uma tarefa relativamente simples pois constitui a rotina diária dos vereadores e 
deputados.

Ressalte-se que num regime democrático o partido que é uma associação de pessoas voltadas à conquista e à manutenção do poder político em uma comunidade emerge como o sujeito principal da ação política pois é a entidade responsável pelo governo. Na qualidade de integrante de um partido o indivíduo pode ser escolhido para ser candidato ou pode apoiar alguém para disputar eleições. Como candidato, se for eleito, poderá tomar várias iniciativas e participar diretamente das decisões políticas. Se apoiar alguém que seja eleito se tornará possível encaminhar petições e apresentar sugestões a ele bem como fazer cobranças e questionar suas atitudes e desempenho. A integração nos partidos é, portanto, uma das formas mais importantes de exercício da cidadania ativa. Tanto nos Estados Unidos quanto na Europa e no Brasil os principais partidos possuem vários milhões de filiados dentre os quais uma quantidade significativa é politicamente ativa.

A Prática de Democracia Digital é muito comum em vários países do mundo, inclusive no nosso, é uma ocorrência típica do atual século embora sua origem se encontre no final do século passado. Esta atividade também é conhecida como e-democracia, ciberdemocracia e democracia virtual. Essencialmente se trata de um intercâmbio entre o sistema político e os cidadãos. Nela a ação política se concretiza através do emprego das ferramentas da comunicação digital as quais viabilizam a participação nos debates entre os governantes e a população e o exercício do voto quando for o caso.

Por meio da democracia digital tornou-se possível incluir crescentemente os cidadãos no processo rotineiro de tomada de decisões pela administração pública. Com a emergência da tecnologia digital já é possível organizar plebiscitos por bairros e até por ruas. Portanto, graças ao aumento dos recursos interativos não faz mais sentido a participação política continuar restrita ao ato de votar uma vez a cada quatro anos.

\section{CONSIDERAÇÕES FINAIS}

Destacamos que a nossa intenção foi a de apenas apresentar sugestões às Escolas do Poder Legislativo. Pensamos inclusive que as que aqui foram expostas não são esgotantes, podem existir outras. Levando em conta as suas peculiaridades, limitações e possibilidades, cabe a cada uma delas selecionar uma ou mais propostas exibidas para efeito de concretização junto aos alunos das escolas pertencentes às redes pública e privada de nosso país.

Realçamos ser necessário não esquecer que para colocar em prática estas sugestões os alunos precisam adquirir determinados conhecimentos e desenvolver algumas habilidades e atitudes. Em relação aos conhecimentos podemos mencionar dentre outros os seguintes tópicos: regime democrático, políticas públicas, partidos políticos, trabalho voluntário, público e privado, desenvolvimento sustentável, democracia virtual, desobediência civil, direitos humanos e movimentos sociais. Quanto às habilidades citamos as de dialogar, debater, argumentar, cooperar 
e resolver conflitos. No que diz respeito às atitudes relacionamos as de tolerância, solidariedade, respeito às diferenças e assunção de compromissos.

Cursos específicos, seminários, oficinas e ciclos de palestras podem ser organizados para este fim. No entanto supomos que nem tudo o que está sendo aqui sugerido pode vir a ser concretizado dada as limitações e especificidades de cada escola do legislativo, entretanto pensamos que algumas dessas sugestões podem ser postas em prática. Considerando o descaso que impera na educação escolar brasileira quanto à formação para o exercício da cidadania qualquer iniciativa em torno dessas propostas se apresenta como algo bastante significativo e precioso pois, indubitavelmente, colabora com esta incipiente e negligenciada formação.

\section{REFERÊNCIAS}

ARENDT, Hannah. A Condição humana. Rio de Janeiro: Forense Universitária, 2007.

BÁRCENA, Fernando. El ofício de la ciudadanía. Barcelona: Paidós, 1997.

BENEVIDES, Maria. A cidadania ativa. São Paulo: Ática, 2000.

BOBBIO, Norberto. Estado governo sociedade. São Paulo: Paz e Terra, 2007.

BUTORI, Margareth. Educação Legislativa: As Escolas do Legislativo nas Câmaras Municipais de Minas Gerais. Revista Estudos Legislativos, v. 8, n. 8, p. 229 a 267, 2014.

CARVALHO, Vânia. Escolas do legislativo e a educação para a cidadania. E-Legis, n. 15, p. 46 61, set./dez, 2014.

CASALECCHI, Gabriel. Cultura Política e Educação Cívica: a confiança política a partir da experiência do parlamento jovem. In: CONGRESSO LATINO AMERICANO DE OPINIÃO PÚBLICA DA WAPOR, IV, Belo Horizonte, 2012. Anais [...]. Belo Horizonte: [s.n.], 2012.

COSSON, Rildo. Escolas do legislativo: escolas de democracia. Brasília: Edições Câmara, 2008.

FREIRE, Paulo. Educação e mudança. Rio de Janeiro: Paz e Terra, 1987.

GIROUX, Henry. La escuela e la lucha por la ciudadanía. Madri: Siglo Veinteuno, 1998.

GRAMSCI, Antonio. Os intelectuais e a organização da cultura. Rio de Janeiro: Civilização Brasileira, 1978.

HABERMAS, Jürgen. Mudança estrutural da esfera pública. Rio de Janeiro: Tempo Brasileiro, 1984.

HOSKINS, Bryony L.; MASCHERINI, Massimiliano. Measuring active citizenship through the development of a composite indicator. Social Indicators Research, v. 90, n. 3, p. 459-488, 2009.

KELLY, Albert. O currículo: teoria e prática. São Paulo: Harper \& Row do Brasil, 1981.

LACLAU, Ernesto; MOUFFE, Chantal. Hegemonia e estratégia socialista: por uma política democrática radical. São Paulo: Intermeios, 2015. 
LUDWIG, Antonio. A reforma do ensino médio e o esquecimento da cidadania. Jornal APASE, v. 28, n. 284, p. 4, jul., 2017.

MARX, Karl. A guerra civil na França. São Paulo: Global, 1986.

MELO, Willian. A Escola do legislativo no contexto da modernização do parlamento brasileiro: um estudo de casos múltiplos: EL-ALMG, CEFOR, ILB-INTERLEGIS. Dissertação (Mestrado em Análise de Políticas Públicas) - Universidade de São Paulo. 2015.

POULANTZAS, Nicos. O Estado, o poder, o socialismo. Rio de Janeiro: Graal, 1985.

REDE EURYDICE, Educação para a cidadania nas escolas da Europa. Comissão Europeia, Luxemburgo, 2017.

SANTOS, Boaventura. Democratizar a democracia: os caminhos da democracia participativa. Rio de Janeiro: Civilização Brasileira, 2002.

SILVA, Otávio; DINIZ, Marina. (Org.). Educação para a democracia: projetos inspiradores das professoras e professores do Brasil. São Paulo: LiberArs, 2018.

WESTHEIMER, Joel. Ensino para a ação democrática. Educação e Realidade, v. 40, n. 2, abr./ jun. 2015.

Artigo recebido em: 2018-05-23.

Artigo reapresentado em: 2019-01-14.

Artigo aceito para publicação em: 2019-03-12. 